\title{
The Impact of the Therapeutic Training Program for the Patients with Dorsal Kyphosis upon Some Variables Associated to it, for the Children under Fifteen. Dr/ Mustafa Ibrahim Ahmed*
}

Research Outline:

The objective of this study is to identify the impact of the therapeutic training program for the patients with Dorsal Kyphosis upon some variables associated to it, for the children under 15 years. To achieve this, the researcher used the experimental approach on a sample of (10) children. A therapeutic training program has been implemented. This program includes exercises for developing the strength of the muscles of the back, stretching and the flexibility of the muscles of the chest and abdomen for (12) weeks, and (36) training units (three training units per week), the first training module for each program is (35 minutes), the second training module for each program is (38 minutes) and the third training module for each program is (48 minutes). The training program is designed according to the principles of Training Science, Sports Medicine, Medical Rehabilitation and Physiotherapy. The results of the study showed that there are statistically significant differences between the premeasurement and the postmeasurement, in favor of the post-measurement. For the members of the research sample in the results of Fraxon angle (degree), the curve of the Spine throughout the smooth vertical surface, the strength of the back muscles, the temperature of the dorsal muscle and the temperature of the squared perverted muscle $(\alpha \leq 0.05)$. The results of the (T) test showed that there are statistically significant differences in the results of the post-measurement of the two groups at the level of technical performance $(T=2.83, \alpha=$ $0.05)$. This is a good indicator regarding the impact of the therapeutic training program for the patients with dorsal Kyphosis, upon some variables associated to it, for children under 15 years of age. The exercises of the proposed rehabilitation program reduce the degree of the Spinal Kyphosis for the members of the examination sample, by the $\mathrm{X}$-Ray test or by the Fraxon angle. The researcher

\footnotetext{
*Assistant Professor of Sports Injury- Faculty of Physical Education- Assiut University.
} 
recommended

implementation

proposed

program in modifying Spinal

Kyphosis in schools; in order to reduce the prevalence of the Spinal Kyphosis. This is the task of the physical education teachers in schools; they have to pay more attention to strengthen the body of the students who suffer spinal deformities, to shield them from the development of this deviation.

\section{The Preface and the Importance of the Research:}

Technological progress has led to lack of movement and lack of effort in performance, which has reflected on many children, making them more exposed to fatal deviations, resulting from the lack of fitness, or from taking wrong positions for long periods while reading, sitting in front of the computer, watching television, using mobile phones, or any other action that may cause a burden on the body in general and on the Spine in particular, which is considered the axis of the human body and a common factor in all activities and movements daily; therefore it is more vulnerable to infection, especially the cervical region.

The integrity of the body and its being devoid from deformities, are closely related to the safety of the respiratory and circulatory systems where the diaphragm is pressed. The presence of any defect in these systems may result in different various deformities in the body. One of the most areas exposed to deformities among children and adolescents is the Kyphosis of the Spine (Hassanein and Ragheb, 64, 1995); because it is the axis on which the Thoracic Cage and arms are based. In addition that it is related to most of the muscles that move the trunk, with a section of the muscles of the upper and lower limbs; therefor "The Spine is the pillar on which the human body is based." (Al-Rahim, Al-Azzawi, 1983, 114). They define (Kyphosis) as "An abnormal increasing in the dorsal area of the Spine, and the effects of this injury are reflected negatively, by the compression over the sternum and the lowing of the Thoracic Cage; thus lead to the contraction of the size of the chest and the vacuum available for the respiratory movement of the lungs" (Hassanein Ragheb, 1995.164). It is worth mentioning that the deviations vary and differ according to the factors that cause and affect on them; there are structural deviations that result from exposing to biomechanical stresses where the first injury is in the muscles. If left untreated, the injury reaches the muscle 
fibers; causing fibrosis, then the injury reaches the bones, making change of the bones shape, which is the most serious thing. In addition to the functional deviations resulting in imbalance of the work of soft tissue and these occur in the muscles and ligaments (Rushdie and Barka, 1997, 247).

Osama Ryad (2001), Muhammed Kadri Bakri and Seham Al-Ghamry (2005) agree that special exercises aim to stimulate muscle tissue, and the targeted codified movement is one of the basic natural methods in the field of integrated treatment of injuries; it depends on various types of exercise, whether negative or positive.

The Spine is one of the most important parts of the human body. It gives the body the right physical strength and performs many important functions such as maintaining the erection of the body and protecting the spinal cord. "Along with being the central axis of the skeleton, which carries the head above, on which the thoracic cage and arms are based, and as separated by most of the muscles that move the trunk with a section of the muscles of the upper and lower limbs; so the Spine serves as the pillar on which the body is based, carries most weights of the body and distribute them equally upon the lower limbs"(Al-Rahim and AlAzzawi 1983, 114).

Loman-Karl

notes that any determination to moderate the body must take into account the proper relationship between the different parts of the body that must be interconnected and cooperated to preserve the body in equilibrium and equalize with minimum energy (LomanKarl 1960, 134).

Research Goals:

The objective of this study is to identify the effectiveness of a program of the therapeutic training for patients with Dorsal Kyphosis, upon some variables associated to it for the children under 15 years, through the following:

1. Preparation of a rehabilitation program to treat the acquired Spinal Kyphosis for the children under 15 years.

2. Detection of the impact of the proposed rehabilitation program related to modifying the Spinal Kyphosis, using the $\mathrm{X}$-ray.

3. Detection of the impact of the proposed rehabilitation program in modifying the acquired Spinal Kyphosis, upon the results of measuring the degree of Kyphosis throughout the smooth vertical surface.

4. Improvement of some of the associated variables (the 
strength of the back muscles the temperature of the dorsal muscle - the temperature of the squared perverted muscle) of the research sample.

\section{Research Hypotheses:}

1. The proposed rehabilitation program has a statistically significant impact, between the pre-test and the post-test of the experimental group, in the favor of the post-test.

2. There are statistically significant differences between the pre-test and post-test in the results of Fraxon angle, by the $\mathrm{X}$-Ray and in favor of the posttest.

3. The proposed rehabilitation program has statistically significant differences between the pre-test and the post-test in the results of the measurement of the degree of Kyphosis, throughout the smooth vertical surface and in favor of the post-test.

4. There are statistically significant differences between the average of the premeasurement and the average of the post-measurement, in the results of (the strength of the back muscles _the temperature of the dorsal muscle - the temperature of the squared perverted muscle) in favor of the post-measurement.

\section{Research Methodology:}

The researcher headed for the experimental approach by using the experimental design for one group, throughout the pre-measurement and the postmeasurement for its suitability and the nature of the research.

\section{The Research Community and Its Sample:}

The research community is middle aged (12-15) year old students, in Qunfudah City for the academic year (2016 2017). In respect of the sample, the sample was deliberately selected from the patients with the moving Spinal Kyphosis, and not with permanent or genetic deformities. Patients with Kyphosis result of wrong sitting, functional sitting or similar. The researcher conducted a medical examination by looking, while the patient is in the position of standing with his the back is adjacent to the wall. After that, (40) students with acquired Spinal Kyphosis, were taken to Qunfudah Hospital, and presented before a group of specialists in rheumatism diseases, fractures and physiotherapy, in order to vary the patients with acquired Dorsal Kyphosis as a result of muscular dystrophy, and to make sure that they are free of pathological or genetic Kyphosis by using radiological examination, students with consistent Kyphosis (genetic or pathological) were eliminated. The outcome of these tests and examinations was the existence of a group of (10) students with acquired Kyphosis, the degree 
of Kyphosis was more than (20) degrees according to Fraxon method used in this research, which measures the degree of Kyphosis, but for the

\section{Table (1)}

normal degree of Kyphosis is (10) degrees according to Fraxon method. Table (1) shows some information about the research sample:

The Arithmetic Average, the Standard Deviation and the Torsion Factor Value of the Total Research Sample in (age - height - mass) $N=10$

\begin{tabular}{c|c|c|c|c|c}
\hline \hline M & Variables & $\begin{array}{c}\text { Measuring } \\
\text { Unit }\end{array}$ & $\begin{array}{c}\text { The } \\
\text { Average }\end{array}$ & $\begin{array}{c}\text { Standard } \\
\text { Deviation }\end{array}$ & $\begin{array}{c}\text { Torsion } \\
\text { Factor }\end{array}$ \\
\hline \hline 1 & Age & year & 13.6 & 1.68 & -1.23 \\
\hline 2 & Height & C.m & 151.40 & 3.24 & 1.01 \\
\hline 3 & Mass & Kgm & 42.70 & 2.57 & -.89 \\
\hline \hline
\end{tabular}

Sampling Homogeneity:

Table (2):

The homogeneity of the Research Sample in the Variables under Study N=10

\begin{tabular}{c|c|c|c|c|c}
\hline \hline M & Variables & $\begin{array}{c}\text { Measurement } \\
\text { Unit }\end{array}$ & Average & $\begin{array}{c}\text { Standard } \\
\text { Deviation }\end{array}$ & $\begin{array}{c}\text { Torsion } \\
\text { Factor }\end{array}$ \\
\hline \hline 1 & $\begin{array}{c}\text { Fraxon angle } \\
\text { The Kyphosis of the } \\
\text { spine throughout the } \\
\text { smooth vertical surface }\end{array}$ & $($ degree $)$ & 21.00 & 2.14 & 0.86 \\
\hline 3 & $\begin{array}{c}\text { The strength of } \\
\text { the back muscles }\end{array}$ & Kgm & 19.29 & 2.30 & 1.25 \\
\hline 4 & $\begin{array}{c}\text { The temperature of } \\
\text { the dorsal muscle }\end{array}$ & $\mathrm{C}^{\mathbf{o}}$ & 32.2 & 0.80 & 1.78 \\
\hline 5 & $\begin{array}{c}\text { The temperature } \\
\text { of the squared } \\
\text { perverted muscle }\end{array}$ & $\mathrm{C}^{\mathbf{o}}$ & 32.77 & 0.60 & 1.01 \\
\hline \hline
\end{tabular}


Table (2) shows that all values of Standard Deviation are lower than Arithmetic Averages. Torsion values range from (0.86: 1.83) and these values are limited between $( \pm 3)$, indicating the homogeneity of the sample. The distribution of the sample indicates a moderate distribution.

\section{Data Collection Methods:}

The tests were used as means of data collection. The researcher took the scientific steps in determining the tests; then he included them in the application of the diagnosis and measurement methods and degrees of Kyphosis, it was presented before a group of doctors specializing in fractures, rheumatism, radiology, physical therapy, medical rehabilitation and sports medicine. The researcher in this application stressed on how to diagnose Kyphosis from the medical point of view, as well as how to measure the Kyphosis and its degrees. The doctors agreed that the best way to detect Kyphosis is seeing, as well as the examination of the patient by standing and the back is adjacent to a smooth vertical surface or a smooth wall. Finally, everyone confirmed that X-ray is the best way to measure the degrees of Kyphosis. It was agreed that the test of measuring the degree of the Spinal Kyphosis, can be done by the Fraxon angle or the X-Ray method, or throughout the smooth vertical surface.

\section{The Measurement of Fraxon}

\section{Angle by the $X$-Ray:}

After the sample was selected and taken to the hospital to take radiographs, the hospital staff removed the device from the parallel position of the land to the vertical position, and then the students were inserted one by one to take radiographs. The first image was (in front of the chest) and the other one was from the side, where the patient with Spinal Kyphosis needed a special position during the radiographs; to prevent any pressure on the top of the Kyphosis, which leads to different Kyphosis angle, this happens while:

The patient took the position that his back was adjacent to the radiator and his arms were down, and the head was adjacent to the device to 
take a picture of the Spine from the front; to observe the position of the deviation while standing in front. And the side position of the patient so that one of the sides of the body was adjacent to the device, and arms bending position over the After the radiogram was head, in order to relieve the pressure from the Spine and stay normal. This method is more accurate in determining how much of the Spine is curved. (Swallow \& Enaylor, 1986, 179-180).

sharpest cusp between the

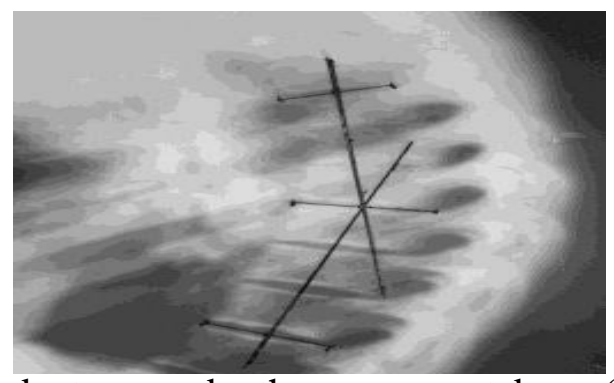

taken, the doctor and the vertebrae $(5,6,7)$, then tick the researcher placed the middle point after the radiographs in the illuminating plate of each student to determine the degree of Kyphosis or Fraxon angle, by measuring with the ruler and the protractor.

The objective of testing the angle of Kyphosis (the curve of the Spine in the dorsal area), by using the (X-Ray) is to determine the degree of the Dorsal kyphosis by extracting the Fraxon degree or angle. It is a method favored by the International Spinal Deformities Research Organization to measure the curves, Fraxon method consists of the following stages:

1. Setting the vertebra, on the radiographic image, with the measurement of the anterior posterior diameter, and then we assign three higher vertebrae and three lower vertebrae from the most curved vertebra, or assigning the higher and the lower vertebrae without deviation, within the natural curve of the spine.

2. Indicating the middle point at the higher vertebra from the three vertebrae above the specific vertebra, or the directly topmost vertebra, and a middle point at the bottom of the lower vertebra.

3. Drawing a line from the middle point of the central curved vertebra where the Kyphosis is intense, to the middle higher point, and then

\section{Assiut Journal For Sport Science Arts}


we draw a line from the middle central point or middle lower point. The angle of the Kyphosis is measured along the bottom line and the upper line by using the protractor and ruler. This angle is called Fraxon angle.

4. The vertical intersecting lines from the upper surface of the higher vertebra and the surface of the bottom line of the lower vertebra are two lines for the measurement of curves in the Spine and are called Fraxon lines or Fraxon angle.

Measuring the degree of Kyphosis throughout the smooth vertical surface:

The

measurement included (40) students with acquired Kyphosis who were appointed by the supervisor. A test that measures the degree of Kyphosis by the measuring tape; where the student stands by making the heels, hips and back adjacent to the wall or the smooth surface, then the supervisor of the test measures the distance between the smooth surface and the seventh cervical vertebra (after defining the location of the seventh cervical vertebra with the magician pen by the expert specialist, the distance to the nearest $\mathrm{cm}$ is measured to determine the degree of Kyphosis angle. The body should be positioned at the natural position to illustrate the whole curves of the body. It is ensured that the smooth vertical surface has been placed to a 90-degree angle using a protractor, as well as using a construction bevel (used to measure the straightness of the wall or door). The tests are then determined by analyzing the content of the available scientific sources and the relevant references in this field. The researcher obtained a set of tests and measurements, which were presented to a group of specialists in the field of measurement and evaluation, all measurements and tests were used where the compatibility ratio was $75 \%$ and more. The tests and measurements included the following:

\section{Devices and Tools Used:}

1. Medical Scale

2. Measuring Tape

3. X-Ray Device

4. Examination Bed

5. Numbered Wooden Box

6. Smooth Vertical Surface

7. Information Application for each student with Spinal Kyphosis

8. Ruler + Protractor

9. Weights Training Hall with its equipment

10. Medical Balls (2), each of them is (1.5) $\mathrm{kg}$ to apply the program

11. Dynamometer to measure the strength of the back muscles

The Rehabilitation Program: 
The rehabilitation program was designed and presented to a group of experts. The program included exercises to develop the strength of the muscles of the back, stretching and the flexibility of the muscles of the chest and abdomen for a period of (12) weeks, and (36) training units (three training units each week) every week (Saturday, Monday, Wednesday). Noting that the period of the first training module for each program is (35 minutes), the second training module for each program is (38 minutes) and the third training module for each program is (48 minutes) (Al-Taie, Munib Abdullah, 2000, 102). The training program was designed according to the principles of the training science, sports medicine, medical rehabilitation and physiotherapy.

The objective of the program is to treat and strengthen the back muscles, stretching and the flexibility of the chest and abdomen muscles, and then benefit from them to mitigate the negative effects of such structural deformity, through the development of muscle groups affected by deformity.
The Foundations of the Proposed Therapeutic Training Program:

By providing the
some
researcher scientific
specialized studies
references and identify the
conducted to
problems caused by neck pain,
and the development of
preventive and curative
programs, which was made
available for researcher in the
field of research and due to his
specialization in the field of
sports health sciences. After
taking the opinion of some
experts in the field of sports
injuries and sports health, some
scientific foundations were
identified that must be taken
into account in designing the
proposed program. These
studies include the work of
many researchers such as
Abdul Majid Awad (2003),
Iman Eid Al-Amir (2004),
Hamdi Ahmed (2006), Fox
(1997).
Expeditionary Experiment:
The First Expeditionary
Experiment:

A visit was made to the members of the working team towards the place of the experiment, in order to identify the type of duties assigned to them, their sequence, the time of implementation of the research experience, the method of registering the tests to avoid errors and overlap in work, this visit was done on $1 / 3 / 2016$. Then the proposed rehabilitation program was designed, the tests and the 
measurements that were applied on the expeditionary experimental sample. The aim of the experiment was to determine the validity of the program, its application, and the validity of the tests and measurements.

\section{The second Expeditionary Experiment:}

The researcher conducted an expeditionary experiment for the tests on a sample of (5) students from outside the sample of the research, which was carried out on 14/3/2016, the aim of the experiment was:

- Identifying the errors and obstacles that may accompany the research.

- Calculating the time required to perform the tests.

- Identifying the validity of the tools used.

- Identifying the efficiency of the work-team and their extent of understanding the tests.

The Progression of the Final Experiment:

To determine the impact of using the proposed rehabilitation program in evaluating the acquired Kyphosis of the Spine, some anthropometric variables, and the physical characteristics, as well as its effect on some variables. The researcher carried out the tests that were previously received and at different times on the research sample. First he began to warm up to prepare the body muscles for the tests and measurements; to prevent any injury may occur to the members of the research sample.

\section{Tests and \\ Pre-}

\section{Measurements:}

The pre-test was conducted on the members of the research sample before starting the rehabilitation program, on 20-22 / 4/2016.

\section{The Period of Implementing the Rehabilitation Program:}

The research sample started with the application of the training program on $1 / 5 / 2016$ and was completed on $1 / 8 / 2016$, for the purpose of reviewing the training program in its final form.

\section{Tests and post- measurements:}

The post-test was conducted on the members of the research sample after the completion of the rehabilitation program, in order to determine the impact of the rehabilitation program in the study variables. This test was performed on 57/ 8/ 2016.

During the Experiment, the Researcher Took into Consideration the Following:

- To guarantee that all members of the research sample are subjected to the same period of time between warming up and starting the tests, the warm-up process is arranged in the interworking mode, so that the time between 
each laboratory and the other is (5 minutes).

- Giving a break between the warm-up period and the first test (5 minutes) to prepare the muscles of the body and its organs for muscle work.

- Measurements (premeasurements and postmeasurements) were carried out under the same conditions, in terms of the location, time of the tests, the equipment and machines used, as well as the sequence of the physical tests. The researcher also ensured that the team was the same one for all tests.

\section{Statistical Means:}

\section{Table (3)}

The statistical description and the significance of the differences between the mean scores of the individuals of the research sample in the pre-measurements and the post-measurements show the results of the measurement of the associated variables in the research $(N=10)$

\begin{tabular}{|c|c|c|c|c|c|}
\hline Variable & Test & Average & $\begin{array}{c}\text { Std. } \\
\text { Deviation }\end{array}$ & Z Value & $\begin{array}{c}\begin{array}{c}\text { Indication } \\
\text { Level }\end{array} \\
\end{array}$ \\
\hline \multirow[t]{2}{*}{ Fraxon Angle } & Pre & 21.00 & 2.14 & \multirow[t]{2}{*}{10.80} & \multirow[t]{2}{*}{ ** } \\
\hline & Post & 11.59 & 1.23 & & \\
\hline \multirow{2}{*}{$\begin{array}{c}\text { Kyphosis of the Spine } \\
\text { by the Smooth } \\
\text { Vertical Surface }\end{array}$} & Pre & 19.29 & 2.30 & \multirow[t]{2}{*}{-5.66} & \multirow[t]{2}{*}{$* *$} \\
\hline & Post & 9.62 & 0.98 & & \\
\hline \multirow{2}{*}{$\begin{array}{l}\text { Strength of the } \\
\text { Back Muscles }\end{array}$} & Pre & 68.15 & 0.07 & \multirow[t]{2}{*}{-3.40} & \multirow[t]{2}{*}{$* *$} \\
\hline & Post & 74.45 & 0.02 & & \\
\hline \multirow{2}{*}{$\begin{array}{l}\text { Temperature of } \\
\text { the Dorsal Muscle }\end{array}$} & Pre & 32.20 & 0.09 & \multirow[t]{2}{*}{-3.31} & \multirow[t]{2}{*}{$* *$} \\
\hline & Post & 33.80 & 0.10 & & \\
\hline \multirow{2}{*}{$\begin{array}{l}\text { Temperature of the } \\
\text { Squared Perverted } \\
\text { Muscle }\end{array}$} & Pre & 32.77 & 0.09 & \multirow[t]{2}{*}{-3.36} & \multirow[t]{2}{*}{$* *$} \\
\hline & Post & 35.45 & 0.03 & & \\
\hline
\end{tabular}
$\alpha \leq 0.05^{*} ; \alpha \leq 0.01^{* *}$

Table (3) shows statistically significant differences at the level of
For the purpose of statistical analysis, the statistical program (16 SPSS) was used, using the following statistical means:

* Average Mean

* Standard Deviation (Std. Deviation)

* Torsion Factor (Skewness)

* Wilcoxon Test

* Improvement percentage \%.

Viewing and Discussing the Results:

To verify the validity of the first hypotheses, tables (3, 4) show the significance of the statistical differences in the results of the measurement of the research variables. 
some of the associated

measurement.

variables, in favor of the post-

Table (4)

The percentage of improvement in the pre-measurement and the postmeasurement of some of the associated variables under study $(\mathrm{N}=10)$

\begin{tabular}{|c|c|c|c|c|}
\hline \multirow{2}{*}{ Variable } & \multicolumn{2}{|c|}{$\begin{array}{c}\begin{array}{c}\text { Measurement } \\
\text { Average }\end{array} \\
\end{array}$} & \multirow{2}{*}{$\begin{array}{l}\text { The difference } \\
\text { between the two } \\
\text { measurements }\end{array}$} & \multirow{2}{*}{$\begin{array}{c}\text { The } \\
\text { Percentage of } \\
\text { Improvement }\end{array}$} \\
\hline & pre & post & & \\
\hline Fraxon Angle (degree) & 21.00 & 11.59 & -9.41 & $44.81 \%$ \\
\hline $\begin{array}{l}\text { Kyphosis of the Spine by the } \\
\text { Smooth Vertical Surface }\end{array}$ & 19.29 & 9.62 & -9.67 & $50.13 \%$ \\
\hline Strength of the Back Muscles & 68.15 & 78.45 & 10.3 & $15.11 \%$ \\
\hline Temperature of the Dorsal Muscle & 32.20 & 36.80 & 4.60 & $14.29 \%$ \\
\hline $\begin{array}{l}\text { Temperature of the Squared } \\
\text { Perverted Muscle }\end{array}$ & 32.77 & 37.45 & 4.68 & $14.28 \%$ \\
\hline \multicolumn{2}{|c|}{$\begin{array}{l}\text { increasing in the percentage of } \\
\text { the variables in the post- } \\
\text { measurements from the pre- } \\
\text { measurements of the research } \\
\text { sample. The highest percentage } \\
\text { is }(50.13 \%) \text { in the favor of the } \\
\text { post-measurement, not for the } \\
\text { pre-measurement, in the } \\
\text { Kyphosis of the Spine } \\
\text { throughout the smooth vertical } \\
\text { surface. While the least } \\
\text { percentage is (14. 28\%) in } \\
\text { favor of the post-measurement, } \\
\text { not for the pre-measurement in }\end{array}$} & \multicolumn{3}{|c|}{$\begin{array}{l}\text { that was subjected to the } \\
\text { proposed therapeutic training } \\
\text { program, because the program } \\
\text { used exercises to strengthen the } \\
\text { back muscles, and due to the } \\
\text { performing these exercises by } \\
\text { the hands, and the binding of } \\
\text { the shoulder belt muscles with } \\
\text { the musculoskeletal groups of } \\
\text { the arms, this is consistent with } \\
\text { what Muhammad Sobhi } \\
\text { Hassanein and Mohamed } \\
\text { Abdulsalam (1995) have } \\
\text { confirmed that strength training } \\
\text { improves and enhances the } \\
\text { muscle strength of the general } \\
\text { muscles }\end{array}$} \\
\hline
\end{tabular}

Assiut Journal For Sport Science Arts 
its turn influences on enriching the metabolism and the work of the blood vessels, activates adrenaline secretion that affects the activation of heart action and metabolism; this helps to raise the temperature of the muscles and readiness to work, as increasing the temperature of the muscles accepted lead to an increase in blood, objectively, to relax the muscles and get rid of nervous tension.

\section{Discussion of Fraxon Angle Measurement Results Using the X-Ray:}

In the previous presentation of the table, we found that there were significant differences in the results of the pre-test and the post-test in favor of the posttest in the research sample. There was a clear improvement in Farxon angle or degree of Kyphosis. The researcher attributed this improvement to the fact that the members of the research sample committed to apply the program vocabulary for three months, which in turn led to modifying the Spine curve throughout the therapeutic training, which was based on the method of gradually increasing repetition in the performance of this training as a result of the stretching exercises. This is in line with what Thulin (1981) pointed out, that "strength and flexibility exercises, in particular, work on modifying and correcting the structural deformities and deviations" (Thulin, 1981, 24).

Some of the results of this study agree with (Arsan, 2004), that there are widespread structural deviations in the Spine, in the following order (left thoracic lateral curve, increased lumbar koilocytosis, right thoracic lateral curve, increased dorsal curving, left lumber lateral curve, decreased lumbar koilocytosis, right lumbar curve, deviation in the form of S). This study was conducted on a sample of (148) students. The study also agrees with (AlDimani, 1999) that the program used, had a positive effect on modifying the deformity of the Shoulders Rotation, in the sample of patients of the middle school students. Some of the results of this test agree with (Al-Rubaie, 2002) that the therapeutic program achieved a clear improvement, in the value of the dorsal Kyphosis angle, and reduced this angle in the sample.

The researcher also believes that the reason of the development in the results of the test, related to the Kyphosis degree (Fraxon angle) in the post-test of the members of the sample of the three categories, is due to that the proposed rehabilitation program contains exercises to improve and 
develop the breathing process, by emphasizing the deep processes of inhalation and exhalation during the performance of the therapeutic training, through the strengthening and stretching of the respiratory muscles and helping muscles, such as abdominal and chest muscles and others. This is confirmed by (Khalil, 1990) "The deformity of dorsal Kyphosis is treated by improving the respiratory function."

The improvement that occurred to the sample members of the post-test related to measuring the degree of Kyphosis (Farxon angle), shows the overall improvement of the sample, and that the proposed rehabilitation program has a significant positive effect on improving the strength of the sample members. This is confirmed by (Hassanein and Ragheb, 1995) that "The treatment at a younger age for the structural deformities makes the treatment easier; using therapeutic physical exercises" (Hassanein and Ragheb, 1995, 256).

The Discussion of the Results of Measuring the Test of Spinal Kyphosis, by the Smooth Vertical Surface:

It is clear from the presentation of the results that there is a clear development in measuring the degree of Kyphosis, throughout the smooth vertical surface of the research sample.

Providing significant differences in the value of (Z), while comparing the pre-test and post-test samples, of the whole sample and at the three age groups, in the curve of the Spine by the smooth vertical surface. The researcher indicates this improvement (the reducing of the Kyphosis degree for the sample members, and the strength of the back muscles), is a result to the implementation of the proposed rehabilitation program. "The strength of the back muscles means a part of the general physical fitness, which provides the individual with overlapping and interrelated fitness such as health, psychological and social fitness" (Abdel Wehab, 1991, 11).

\section{Conclusions:}

In light of the study and its results, the following has been achieved:

1. The implement of the proposed rehabilitation program reduces the degree of the Spinal Kyphosis, for the sample members related to the $\mathrm{X}$-ray test, or the Fraxon angle. 2 . The degree of Kyphosis throughout the smooth vertical surface: any decrease in the degree of Kyphosis is a change in the Spine, and this decrease led to a low degree of Kyphosis and a clear 
improvement in the external body structure (the Spine).

Recommendations:

In light of the researcher's results and within the objectives of the research, the researcher recommends:

1. To implement the proposed rehabilitation program for modifying the Spinal Kyphosis in schools; in order to reduce the prevalence of deviation of the Spinal Kyphosis.

2 - The importance of attention to the body structure, by the teachers of physical education in schools towards the students with spinal deformities, paying attention to prevent them from the development of this deviation.

3. The physical education teachers shall be trained to this therapeutic programs, for such deformities and other distortions.

4. Raising awareness among middle school students of healthy habits, standing and sitting, and being aware that such deviations are cumulative results of wrong habits.

5. Conducting further researches and tests on the spinal deviations.

6. The importance of using the iron halls, physiotherapy equipment and therapeutic pools, to treat such deformities.

Arabic and English
References:

1. Osama Riyad (2001): Physical Therapy and Rehabilitation of
Athletes, Dar Al-Fikr Al-Arabi, First Edition, Cairo.

2. Eman Eid Al-Amir (2004):

"A Proposed Program for the Rehabilitation of Women with Neck and Shoulder Pain", published research, the first scientific conference, hockey between reality and hope, Zagazig University.

3. Hassanein, Mohamed Sobhi, Ragheb, Mohamed Abdul Salam (1995): The Proper Texture Body for All, 1, Dar Al-Fikr Al-Arabi, Cairo.

4. Hamdy Ahmed Abdul Ati (2006): "The Effect of Rehabilitation Training Program for the Treatment of Neck Roughness", unpublished Master Thesis, Faculty of Physical Education, Tanta University, (2006).

5. Khalil, Samiea (1990): Therapeutic Sports, Dar alHikma Press, Baghdad.

6. Al-Dimani, Raouf's son (1999): "The Effect of Using a Physical Training Program on Some Anthropometric and Physical Variables in Modifying the Deformity of Shoulder Rotation", unpublished Master Thesis, Faculty of Physical Education, Baghdad University, Baghdad.

7. Al-Rabaie, Suhad Hassib Abdul Hamid (2000): "The Effect of Therapeutic Program on Distortions of the Dorsal Kyphosis in Some Basic Skills", published Master Thesis, Faculty of Physical 
Education, University, Baghdad.

8. Al-Rahim, Abdul Rahman Mahmoud, Al-Azzawi, Hani Taha (1983): Principles of Anatomy, T3, Dar Al-Hurya for Printing, Baghdad, Iraq.

9. Rushdi, Mohamed Adel and Bureka, Mohamed Jarallah (1997): Spine Injuries

Mechanism, Knowledge

Facility, Alexandria.

10. Al-Taei, Munib Abdullah Fathi Hussain (2000): "The Effect of Using Different Therapeutic Methods in Modifying the Deformation of Flexible Foot Flattening and Some Kinetic Capacities", unpublished Master Thesis, Faculty of Physical Education, Baghdad.

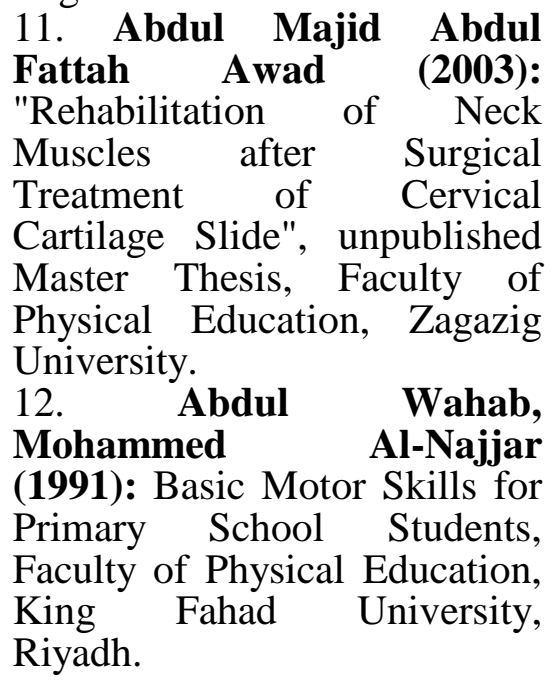

13. Arsan, Abdul Basit (2004): Spinal Deviations among the Students of the Three High Classes in the Basic Education, Journal of Special Studies, University of Jordan, Deanship of Scientific Research, Jordan.

14. Mohamed Subhi Hassanein \& Mohamed Abdul Salam Ragheb (1995): Proper Texture Body for All, Dar Al-Fikr Al-Arabi, First Edition, Cairo.

15. Mohammed Kadri Bakri \& Siham Assayed Al-Ghamri (2005): Sports Injuries and Physical Rehabilitation, Dar Al-Manar Press, Cairo.

16. Fox. B. Sahuguilloo (1997): Reactive Arthritis with Losion at The Cervical Spine, jan, 361, 1, 125- 129.

17- Lomans Charles. Young. Cavl. Hareh (1960): "Postural Fillness Significance and Variance", Henry Kimpton 134 great pottand street. W. L. London.

18- Swallow, R. A \& Enaylor (1960): Clark's positioning in radiography, $11^{\text {th }}$ ed., William Henemann Medical Books, London.

19- Thulin J. G, (1981): "Principles of Posture Gymnastics" felp, Bulletin, Vol. 51, No. 4. 